775 WORK ABILITY TRAINING PROVIDED BY OCCUPATIONAL HEALTH CARE REDUCES SICKNESS ABSENCES AND WORK DISABILITY RISKS

T Toikka*, S Julkunen, M Korjonen, R Mannonen, M Weman. Occupational Health Helsinki, Helsinki, Finland

\subsection{6/oemed-2018-ICOHabstracts. 1576}

Introduction Work ability training provided by the Occupational Health Helsinki is a new group intervention for Helsinki's municipal employees whose risk for poor work ability has increased. Participants are selected in occupational health receptions. Work ability training includes three groups: musculoskeletal symptoms, mental wellbeing and MBO risk. The aim is to find the best ways to support coping and personal change.

The work ability training starts with a 5 day rehabilitation period. Thereafter, the employee participates for group meetings for one year (total of 4 contacts), which are run by occupational healthcare coaches. The Occupational Health Helsinki evaluated the effectiveness of the work ability training on participants' health, work ability and sickness absence.

Methods Participants' work ability, self-efficacy, work-related well-being, lifestyle risks were measured with questionnaire before and after the work ability training in years 2014-2016 $(n=676)$.

Analyses of the questionnaires were divided into three groups according to the objectives of the interventions. Sickness absences of those who participated in the $2014(n=119)$ for one-year training were surveyed a year before (2013) and after training (2016). Comparisons were made between the changes in two groups: participation 3-4 times and 0-2 times. The statistical significance limit was set at $\mathrm{p}<0.05$ for all analyses. Data were analysed using SPSS.

Results Sickness absenteeism was reduced 19\% only by those who participated actively in full-year coaching $(n=81)$, absenteeism was increased $34 \%$ by those who only participated in the rehabilitation period $(n=38)$. Despite a large percentage change, the result was not statistically significant.

Perceived work ability and recovery improved, depression risk, insomnia and fatigue, stress and prolonged pain decreased in all groups. Changes were statistically significant $(\mathrm{p}<0,05)$.

Conclusion Commitment to work ability training provided by occupational healthcare is effective in improving work ability and reducing sickness absence and health risks.

\section{PREVENTION OF DISABILITY PENSION IN OCCUPATIONAL HEALTH CARE - A FIVE YEAR FOLLOW- UP OF IMPROVEMENT IN THE QUALITY NETWORK}

\footnotetext{
${ }^{1} \mathrm{~J}$ Kuronen* ${ }^{*}{ }^{2} \mathrm{~K}$ Winell, ${ }^{3} \mathrm{~S}$ Riekki, ${ }^{4} \mathrm{~K}$ Räsänen. ${ }^{1}$ Etelä-Savon Työterveys Oy, Mikkeli, Finland; ${ }^{2}$ Conmedic Oy, Espoo, Finland; ${ }^{3}$ Keva, Helsinki, Finland; ${ }^{4}$ University of Eastern Finland, Kuopio, Finland
}

\subsection{6/oemed-2018-ICOHabstracts. 1577}

Introduction Early retirement due to mental illness or disease in musculoskeletal system has been a major problem in Finland. Municipality based occupational health service (OHS) units formed in 2011 the Finnish Occupational Health Service Quality Network (FOHSQN), which aimed to prevent disability pensions by improving the OHS processes and continuous measurements of quality and outcomes. We aimed to compare the outcomes of FOHSQN to all other actors in the public employee pensions system during the years 2011-2016.

Methods This study includes all municipality employees in Finland, whose pension insurance is provided by Keva (the public pension provider in Finland). The incidence of early retirement due to disability pension among the OHS units in the FOHSQN was compared to the incidence in the public employee pensions system for each study year. We counted indexes (partial/full pension) to describe if OHS units were able together with the employers to favour partial disability pensions.

Results The yearly number of disability pensions varied from 774 to 984 in the FOHSQN and from 4384 to 5404 in the whole public employee pensions system during 2011-2016. The incidence of disability pension was $1.10 \%$ in 2011 and $0.93 \%$ in 2016 in the FOHSQN and the corresponding figures in the total pension system $1.07 \%$ and $0.92 \%$ ( $\mathrm{p}$ for trend 0.799). Partial/full- index increased for disability pensions from 1.17 to 2.31 in the FOHSQN and from 1.22 to 1.81 in the total pension system ( $\mathrm{p}$ for trend 0.078)

Discussion Work disability pension incidence declined both in the total municipality pension system and FOHSQN. Also the partial disability pension became proportionally more frequent in both groups. The trends favoured the results in the FOHSQN, but the differences were not statistically significant. Pension data can be used as an outcome measure in comparison of OHS units.

\section{ASSESSMENT OF PHYSICAL HEALTH AND FATIGUE AMONG ANCILLARY STAFF IN A HEALTHCARE INSTITUTION: A PILOT STUDY}

Dwee Wee Lim*, Lay Tin Lee, Joseph Lee. Occupational Health Services, Tan Tock Seng Hospital, Singapore

\subsection{6/oemed-2018-ICOHabstracts.1578}

Introduction Ancillary staff in the hospital includes patient service associate, operating theatre attendant and executive who support healthcare workers in providing services to patient. This pilot study aims to assess the physical health and fatigue in this group of employees in the hospital to design an appropriate targeted intervention.

Methods This cross-sectional study collected data on ancillary staff who volunteered to participate in a 12 week exercise program. Data collected include demographics, anthropometric measurements, and exercise duration per week. Short physical performance battery (SPPD), timed-10 $\mathrm{m}$ walk test and grip strength for upper limb were assessed to derive score for aerobic fitness, muscular strength, balance and flexibility with maximum score of 100. Fatigue was assessed using Chalder Fatigue Scale which is able to assess both physical and mental fatigue. Total fatigue score was dichotomized to fatigued $(>3)$ and non-fatigued employees $(\leq 3)$.

Results There were a total of 78 participants, with mean age of 54.8 years. Majority were female (64.1\%) and Chinese (48.7\%). Of the participants, $12(15.6 \%)$ were fatigued. Average body mass index (BMI) and waist-hip ratio (WHR) were $25.8 \mathrm{~kg} / \mathrm{m}^{2}$ and 0.87 respectively. In univariate analysis, age was not associated with any of the physical health score. Male had significantly higher aerobic fitness score compared to female $(65.2$ vs 85.7, $\mathrm{p}<0.001)$. Higher BMI is associated with lower aerobic fitness $(p=0.001)$. All subscale for physical 
health were associated with physical fatigue, but only higher muscular strength is associate with lower mental fatigue score $(\mathrm{p}=0.038)$. In multivariate analysis, muscular strength and balance were independently associated with fatigued, OR of 0.94 (95\% CI: 0.90 to 0.99 ) and 0.95 (95\% CI: 0.92 to 0.99 ) respectively.

Conclusion Physical health and fatigue are related. Impact of physical health interventions on fatigue would require further studies.

\section{COMPARING DISABILITY AND RETURN TO WORK OUTCOMES BETWEEN ALTERNATIVE AND TRADITIONAL WORKERS' COMPENSATION PROGRAMS}

${ }^{1}$ A Ryan*, ${ }^{2} \mathrm{~K}$ Schofield. 'University of Minnesota Minneapolis, USA; ${ }^{2}$ University of Minnesota Duluth, USA

\subsection{6/oemed-2018-ICOHabstracts. 1579}

Introduction In 1995, Minnesota, United States, passed legislation to allow for an alternative workers' compensation system and the Union Construction Workers' Compensation Program (UCWCP) was developed. Its goals include the use of preapproved medical and rehabilitation providers, dispute resolution, and prioritising a quick and safe return to work. The aim of this study is to determine if differences in recoveryrelated outcomes exist between UCWCP and traditional workers' compensation programs (TWCP).

Methods Workers' compensation claim data for the period 2003-2016 were obtained from the Minnesota Department of Labour and Industry. Claims were classified as processed through UCWCP or TWCP. Outcomes for this study included: permanent partial disability (PPD) and Temporary Total Disability (TTD). The relative risk (RR) of incurring PPD and sustained TTD in UCWCP versus TWCP was calculated using $\log$ binomial regression. Ordered logistic regression models were utilised to calculate the odds of higher percentages of PPD in UCWCP. All estimates were adjusted for age, gender, and insurance carrier.

Results Of 33682 claims, 3269 (9.7\%) were processed through UCWCP. The mean claim durations for UCWCP and TWCP were 54 and 49 weeks, respectively. While UCWCP claims, versus TWCP, were associated with an increased risk of PPD $(R R=1.2,95 \% \mathrm{CI}$ : 1.1 to 1.3$)$, they had increased odds of lower percent PPD (Odds Ratio=1.2, 95\% CI: 1.1 to 1.4). Sustained TTD was more likely in UCWCP compared to TWCP (RR $=2.0,95 \% \mathrm{CI}: 1.4$ to 3.0$)$.

Conclusions While the increased risks of permanent partial and sustained temporary total disability ratings among UCWCP claims may reflect higher severity, the lower percentage of disability could result from improvements in access and quality of healthcare treatments. Further work will identify and control for relevant severity indicators.

\section{SWIMMING AGAINST THE CURRENT: A META- ETHNOGRAPHY EXAMINING LIVING WITH ARTHRITIS AND BEING EMPLOYED}

RJ Purc-Stephenson*, H Smith, J Dostie. University of Alberta, Camrose, Canada
Introduction Arthritis and related rheumatic conditions are common causes of work disability in Canada and the United States, with job loss ranging between 37\%-60\% within the first 10 years of diagnosis. As diagnosis commonly occurs between the ages of 30-60 years, the symptoms of pain, limited mobility, and fatigue can seriously disrupt and hinder work lives. While research has examined disability and work loss among persons with arthritis (PwA), little is known about what they do to maintain employment. Our goal was to understand how PwA experience employment and to use this information to build a model describing what they need to sustain employment.

Methods We searched published studies on arthritis and employment from six electronic databases (1980-2017) and bibliographical reviews using a combination of keywords related to arthritis, employment, and qualitative research. Our search yielded 748 articles, and after applying the inclusion criteria, 17 studies remained. Two reviewers independently reviewed, critically appraised, and extracted concepts from each study in chronological order.

Result Using a meta-ethnographic process, we identified seven themes highlighting the common issues experienced by PwA. Using these themes, we developed a process model that illustrates how individual factors (i.e., physical symptoms, selfawareness, meaning of work) influence work-sustainability strategies that are initially privately managed (i.e., personal adjustments, medical treatment, family support); however, when symptoms become too difficult to conceal, individuals will disclose their condition to their employer so that they can draw upon additional work-sustainability strategies (i.e., work accommodations, supervisor and co-worker support, insurers). Individuals engage in these strategies to maintain a 'non-ill' identity and remain in their current job for as long as possible.

Discussion Our findings will help rehabilitation specialists, employers, and researchers understand what PwA may need to sustain meaningful employment outcomes. Implications to workplace policies and practices are discussed.

\section{A TAILORED WORK- RELATED SUPPORT INTERVENTION FOR GASTRO-INTESTINAL CANCER PATIENTS: INTERVENTION PROTOCOL}

${ }^{1}$ AnneClaire GNM Zaman*, 'Angela GEM de Boer, ${ }^{2}$ Kristien MAJ Tytgat, ${ }^{3,4}$ Jean HG Klinkenbijl, 'Monique HW Frings-Dresen. 'Academic Medical Centre, University of Amsterdam, Department Coronel Institute of Occupational Health, Amsterdam Public Health research institute, Amsterdam The Netherlands; ${ }^{2}$ Academic Medical Centre, University of Amsterdam, Department of gastroenterology, Amsterdam, The Netherlands; ${ }^{3}$ Gelre Hospital, Department of Surgery, Apeldoorn, The Netherlands; ${ }^{4}$ University of Amsterdam, Amsterdam, The Netherlands

\subsection{6/oemed-2018-ICOHabstracts. 1581}

Introduction The objective was to develop a tailored intervention for work- related problems to support gastro-intestinal (GI) cancer patients and to evaluate its cost-effectiveness compared with the usual care provided.

Methods We designed a multicentre randomised controlled trial with a follow-up time of twelve months. Included participants will be aged 18-63 years, diagnosed with a curative primary GI cancer and employed at time of diagnosis. The participants will be randomised to the intervention or to usual care. 